\title{
Review Article \\ Development of Cardiovascular Indices of Acute Pain Responding in Infants: A Systematic Review
}

\author{
Jordana A. Waxman, ${ }^{1}$ Rebecca R. Pillai Riddell, ${ }^{1,2,3}$ Paula Tablon, \\ Louis A. Schmidt, ${ }^{4}$ and Angelina Pinhasov ${ }^{1}$ \\ ${ }^{1}$ Department of Psychology, York University, Toronto, ON, Canada \\ ${ }^{2}$ Hospital for Sick Children, Toronto, ON, Canada \\ ${ }^{3}$ Department of Psychiatry, University of Toronto, Toronto, ON, Canada \\ ${ }^{4}$ Department of Psychology, Neuroscience, and Behaviour, McMaster University, Hamilton, ON, Canada
}

Correspondence should be addressed to Rebecca R. Pillai Riddell; rpr@yorku.ca

Received 18 August 2015; Accepted 20 August 2015

\begin{abstract}
Copyright (C) 2016 Jordana A. Waxman et al. This is an open access article distributed under the Creative Commons Attribution License, which permits unrestricted use, distribution, and reproduction in any medium, provided the original work is properly cited.

Background. Cardiovascular indices of pain are pervasive in the hospital setting. However, no prospective research has examined the development of cardiac responses to acutely painful procedures in the first year of life. Objectives. Our main goal was to synthesize existing evidence regarding the development of cardiovascular responses to acutely painful medical procedures over the first year of life in preterm and term born infants. Methods. A systematic search retrieved 6994 articles to review against inclusion criteria. A total of 41 studies were included in the review. Results. In response to acutely painful procedures, most infants had an increase in mean heart rate (HR) that varied in magnitude both across and within gestational and postnatal ages. Research in the area of HR variability has been inconsistent, limiting conclusions. Conclusions. Longitudinal research is needed to further understand the inherent variability of cardiovascular pain responses across and within gestational and postnatal ages and the causes for the variability.
\end{abstract}

\section{Introduction}

Although skepticism towards infant pain characterized much of the 20th century research and clinical practices [1], it is now well established that infants' pain transmission pathways in the brain are fully developed by 22 to 24 weeks of gestation [2]. Conversely, pain inhibitory pathways are not fully developed in infants, suggesting that infants may feel even more pain than older children [2]. Improper management of infant acute pain has been associated with various short- and longterm negative physiological and psychological consequences. Specifically, increased metabolic rate during painful experiences has been associated with short-term consequences such as exacerbating injury, increased potential for chronic pain, delayed wound healing, increased risk of infection, and alterations in pain sensitivity [3-5]. Additionally, long-lasting consequences include delays in motor and brain development, as well as deficits in cognition and emotion regulation [6-11]. Therefore, it is important to establish empirically based behavioural and physiological pain assessment tools that can be utilized in infancy to begin the pain management process.

The major challenge with infant pain assessment is that neonates cannot self-report their subjective experience of pain. Moreover, there is a lack of agreement on the best proxy modality of assessing infant pain, whether it is cortical, biochemical, physiological, or behavioural [12]. Moreover, recent work has suggested discordance not only among modalities $[13,14]$, but also within an assessment modality [15]. For example, the validity and reliability of physiological measures of infant pain are presently disputed, due to the fact that these measures are influenced by additional variables or covariates that have not been properly been taken into account (e.g., infection and respiratory rate) [16].

Despite the above-mentioned disputes, cardiophysiological indices of pain, such as heart rate (HR) and HR variability (HRV), are pervasive in the hospital setting [17]. Indeed, cardiac measures are well-established noninvasive proxies 
of cardiac autonomic control and have been integrated in well-established pain assessment tools for preterm and term born infants, as well as young children [3, 18-23]. However, despite this integration into mainstream clinical practice, there appears to be no research that has systematically examined the developmental differences of cardiac responses to acutely painful procedures in either preterm or term born infants longitudinally. Systematic research with a behavioural indicator of pain has suggested extreme variability across the first year of life [15] and given the established differences in nervous system processing between preterm and full term born infants [24-27], it behooves researchers to more systematically examine cardiac responding to pain and its validity as a proxy for pain perception $[28,29]$. The purpose of this systematic review is to synthesize existing evidence on the development of cardiovascular responses to acutely painful medical procedures over the first year of life in both preterm and term born infants. Studies will be organized first according to the age of the infant at measurement, then subdivided by the gestational age at birth, and then further subdivided by the type of cardiac measurement.

\section{Method}

2.1. Search Strategy. With the assistance of an academic librarian at the University of Toronto, a systematic search was conducted in Medline, Embase, PsychINFO, and CINAHL in July 2014 for English-language references. Searches were limited to articles published from 1970 to 2014 in order to encompass historical and contemporary articles and reviews. Search terms related to acute pain procedures, cardiovascular measures, and infants ( $0-3$ years of age) were systematically paired (see Supplementary File 1 for Medline search in Supplementary Material available online at http://dx.doi.org/10.1155/2016/8458696). We also hand searched reference lists of relevant studies and systematic reviews on cardiovascular responses to acute pain in infants. Our review followed an a priori protocol according to the Preferred Reporting Items for Systematic Reviews and MetaAnalyses (PRISMA) guidelines [30]. The review protocol was registered on the PROSPERO website before data extraction (registration number CRD42015016398) [7].

2.2. Inclusion and Exclusion Criteria and Study Selection. We included prospective observational or descriptive studies of individuals equal to or under 3 years of age undergoing an acutely painful procedure, which was monitored using a cardiovascular measure. Our definition of observational studies included cohort studies in which participants were prospectively identified and followed up during acutely painful procedures using cardiovascular indices, as well as cross-sectional studies that observed an acutely painful procedure using a cardiovascular measure across different gestational or postnatal ages. We also included control group data from pain manipulation studies and prospective randomized or randomized controlled trials (RCTs) that investigated the effectiveness of pain management strategies using cardiovascular measures.

Studies were excluded if they described nonhuman animal models of pain, did not measure an acutely painful event nor include a cardiovascular measure of acute pain, were prospective randomized, RCTs, or pain manipulations that did not include a control group, were review articles, case studies, or conference abstracts, or studies that included participants that differed in age at measurement (i.e., collapsing over one or more months), or gestational age (GA) (i.e., collapsing across at least four months of GA). Of note, most studies that were discarded for collapsing over age of measurement were averaging over age spans within infancy greater than 6 months.

Two authors designed the abstract selection criteria with an initial selection of 500 abstracts (Jordana A. Waxman and Rebecca R. Pillai Riddell). Three authors (Angelina Pinhasov, Jordana A. Waxman, and Paula Tablon) independently read and selected from all the retrieved references and abstracts. Any disagreements between reviewers were resolved through discussion. The percent agreement between the raters ranged from 0.96 to 1.0. Full texts of potentially eligible studies were retrieved (see Figure 1).

2.3. Data Extraction and Quality Assessment. A database was created recording GA at birth, postnatal age at measurement, a description of the cardiovascular results, and any covariates that were included when analyzing whether there were differences in cardiovascular measures following an acutely painful medical procedure. It was important to investigate covariates included in the studies, as there are a number of physiological and behavioural variables known to affect the cardiovascular system [16]. We reasoned that delving into what variables were controlled for might help explain why there is variability in cardiovascular measures. Where information was incomplete, the authors were contacted by email.

Due to the fact that a gold-standard quality assessment measure was not available for observational studies [31], a modified checklist combining Downs and Black [32] and Crombie and McQuay [33] was utilized (see Supplementary File 2 for the checklist). These measures were chosen based on a multidisciplinary collaborative review in the field discussing quality in case-control, cohort, and cross-sectional studies [31]. Fifty percent of the extractions were consensus coded for quality scores to ensure reliability. Disagreements were minimal and were resolved through discussion to obtain a final score for each paper. Criteria were scored as "Yes" (1), "No" (0), or "Unable to Determine." Positively scored criteria were added to obtain a total quality score for the paper. The maximum obtainable score was 20 for cross-sectional studies and 21 for cohort studies. The results were expressed as percentages of the total obtainable score.

2.4. Analysis. We aimed to synthesize evidence on the development of cardiovascular responses to acutely painful procedures in preterm and term born infants. For qualitative analysis, group-specific data were first separated by age at measurement and subsequently subdivided by GA at birth, as well as cardiovascular outcome measures (i.e., mean heart rate $(\mathrm{HR}), \mathrm{HR}$ change, maximum $\mathrm{HR}$, total heart rate variability (total HRV), low frequency heart rate variability (LF HRV), high frequency heart rate variability (HF HRV), and low frequency/high frequency ratio (LF/HF ratio)). 
PRISMA 2009 flow diagram

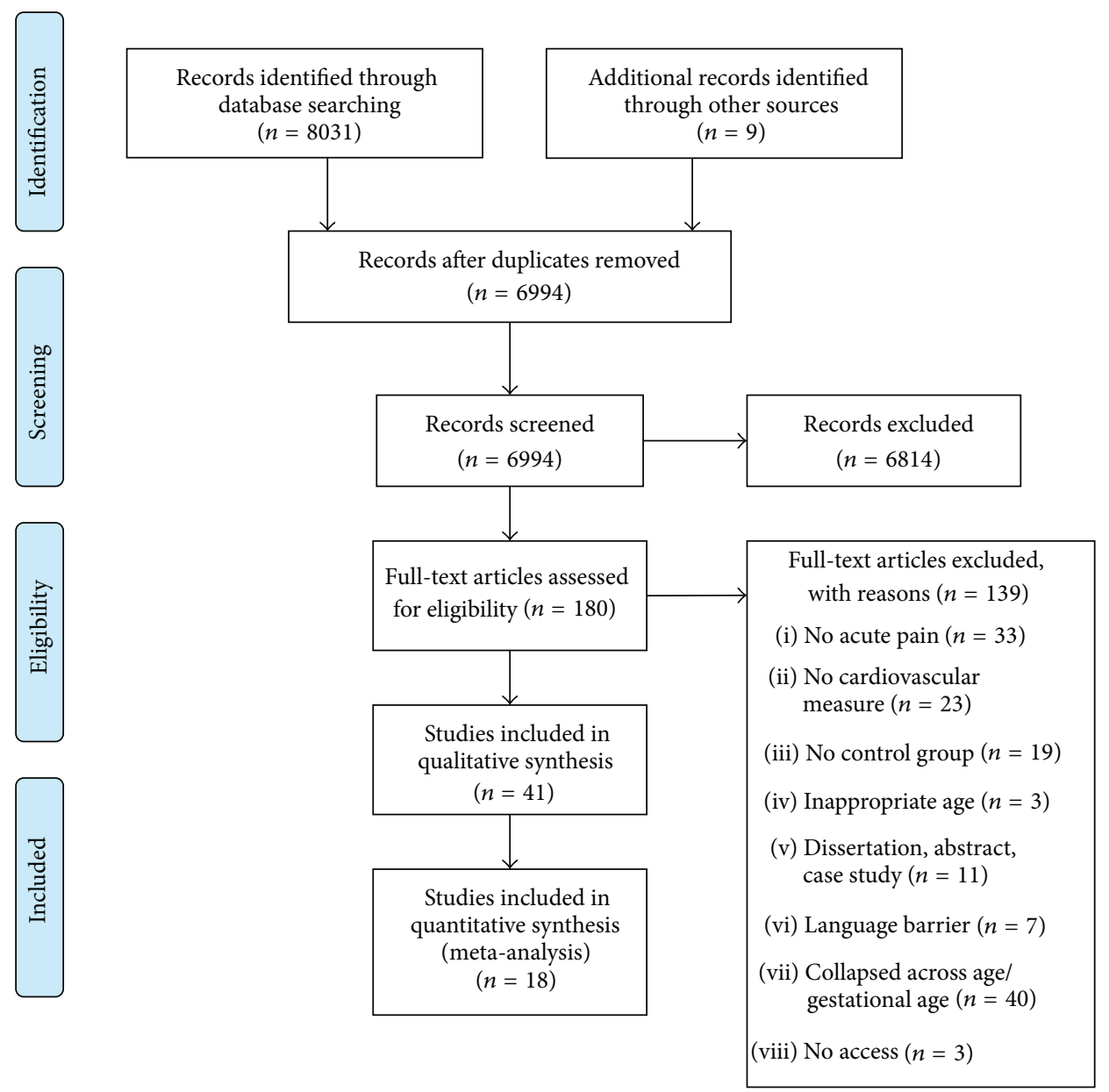

FIGURE 1: Included study flow chart following PRISMA guidelines.

\section{Results}

3.1. Studies Included. We identified 6994 articles from the electronic searches after removal of duplicates. These articles were then reviewed by title and abstract and were included or excluded based on a priori selection criteria. A total of 180 articles were then reviewed by full-text review, and of these, 41 articles (involving 1552 participants) fulfilled the inclusion criteria [24-27, 34-71]. These studies underwent quality assessment and data extraction and were included in the final review.

3.2. Study Characteristics. Table 1 provides a detailed overview of the studies included, including sample size, country of origin, GA at birth, postnatal age at measurement, acutely painful procedure, cardiovascular measure, study design, and quality assessment score.

Generally speaking, a quarter of the studies were from Canada, a quarter from the United States, and a quarter from Europe, with the remaining studies coming from Asia, the Middle East, and Brazil. The majority of studies were randomized trials and encompassed infants born between 24 and 42 weeks GA that were tested between postnatal day 1 and postnatal month 4 . The most common acutely painful procedure that was utilized in the studies was heel stick, and mean HR was the most frequently used cardiovascular measure. In terms of the range of quality scores for the papers, the lowest score was $40 \%$ [27], the median quality score for the papers was $75 \%$, and the highest score was $86 \%$ [69].

Age categorizations were difficult to obtain due to the variability between studies in the age groups they analyzed. Based on the available data, the results will be organized by the following postnatal ages (i.e., age at measurement): 7 postnatal days or less, 1 to 2 postnatal weeks, 3 postnatal weeks, and 1,2, 3, and 4 postnatal months. Since the majority of data are published on infants within the first 7 postnatal days, tables will only be presented for these studies (see Tables 3-9). In addition, within each age at measurement category, results will then be subdivided by accepted categorizations of GAs [72] and the cardiovascular measures examined. Due to the large variability in choice of covariates only the presence of covariates will be noted, with a comprehensive list being provided in Table 2 across studies. 


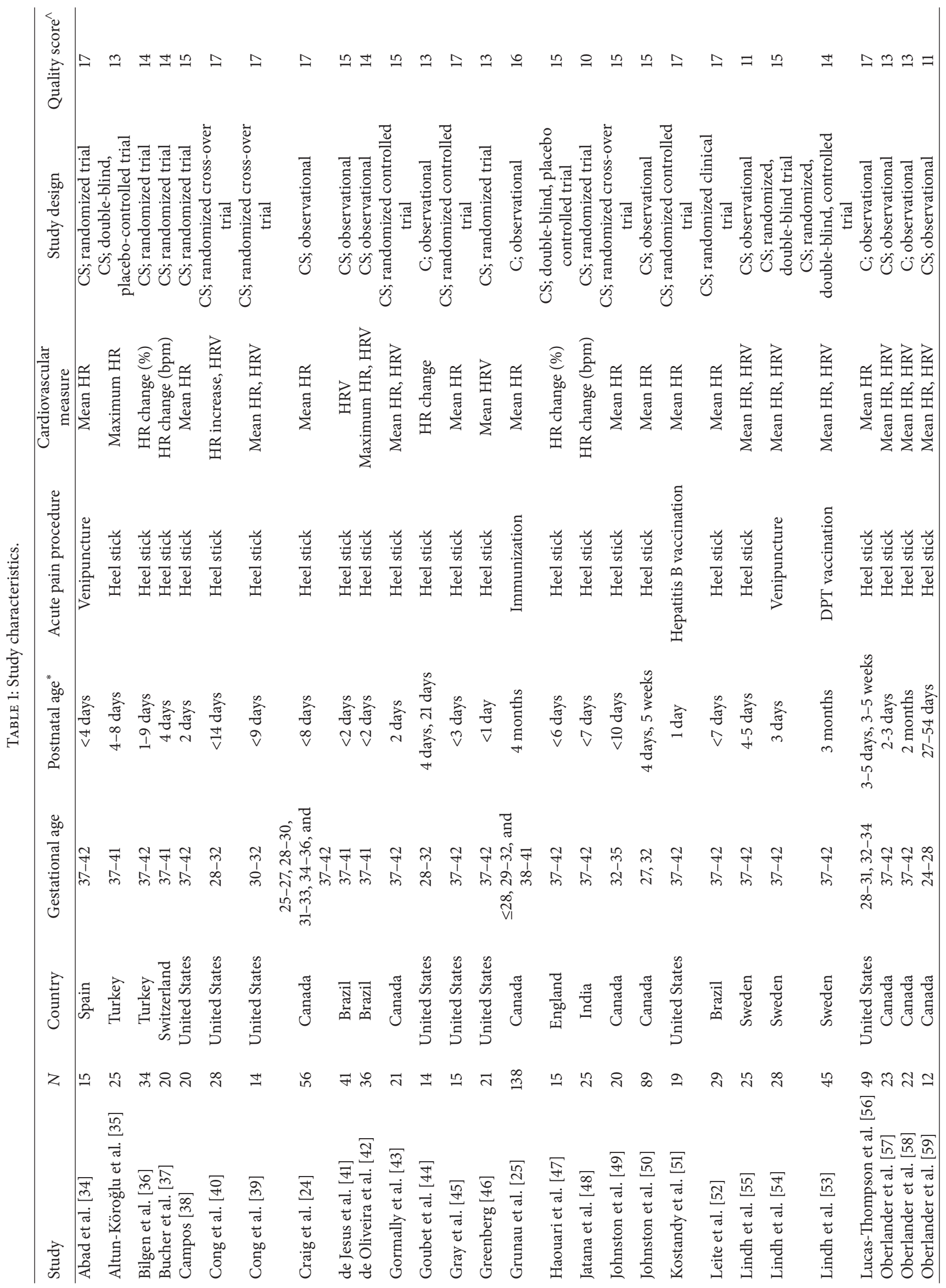




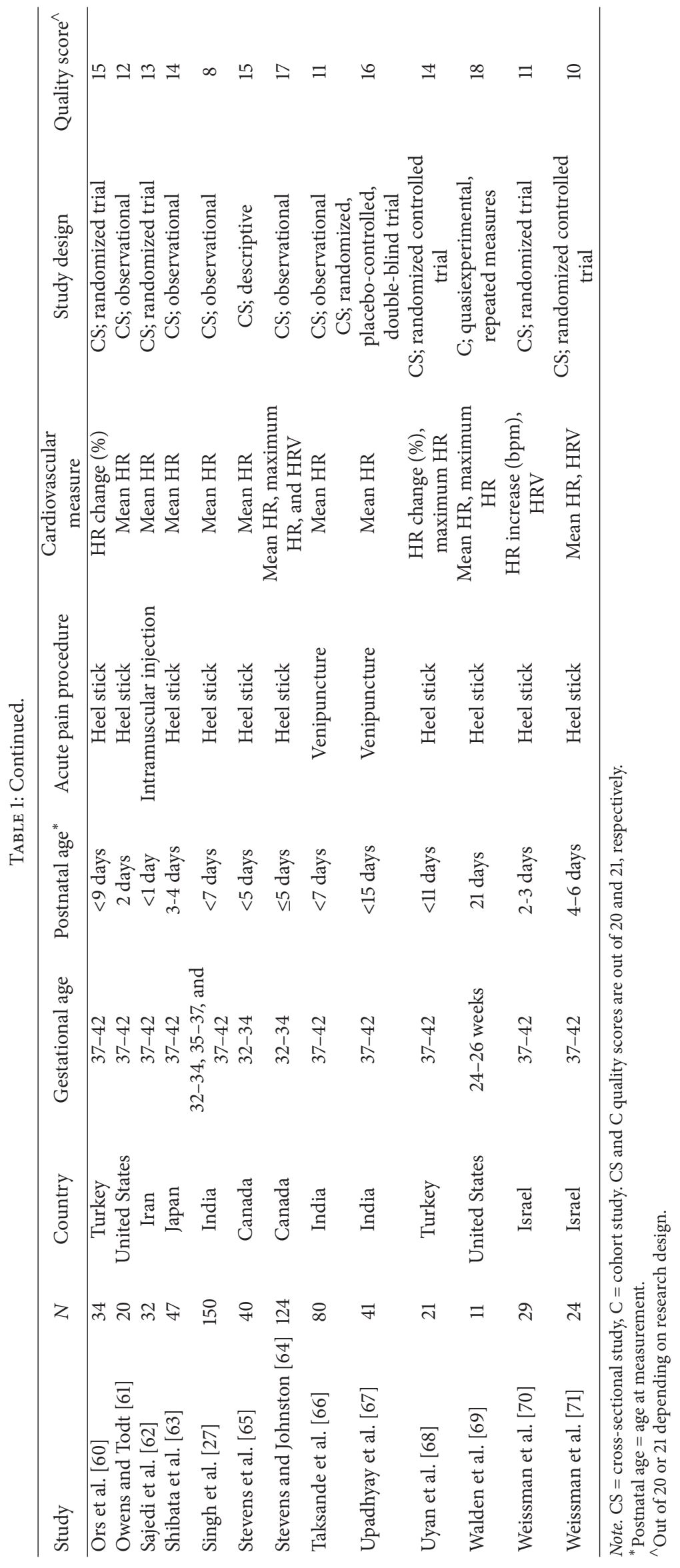


TABLE 2: Description of study covariates included in the cardiovascular analyses.

\begin{tabular}{|c|c|}
\hline Study & Covariates \\
\hline Abad et al. [34] & N/A \\
\hline Altun-Köroğlu et al. [35] & $\mathrm{N} / \mathrm{A}$ \\
\hline Bilgen et al. [36] & $\mathrm{N} / \mathrm{A}$ \\
\hline Bucher et al. [37] & Sex, nurse, number of lances needed, baseline heart rate, and activity \\
\hline Campos [38] & $\begin{array}{l}\text { The number of additional sticks required to obtain the blood sample, the duration of the heel } \\
\text { stick, the frequency of crying, and the average HR }\end{array}$ \\
\hline Cong et al. [40] & $\mathrm{N} / \mathrm{A}$ \\
\hline Cong et al. [39] & N/A \\
\hline Craig et al. [24] & $\mathrm{N} / \mathrm{A}$ \\
\hline de Jesus et al. [41] & $\begin{array}{l}\text { Gestational age, birth weight, sex, mode of delivery, diabetic mothers, breast-fed one hour before } \\
\text { puncture, and received oral glucose }\end{array}$ \\
\hline de Oliveira et al. [42] & PIPP score in the period before the heel prick \\
\hline Gormally et al. [43] & $\begin{array}{l}\text { Preintervention baseline (percentage of time crying in the last two minutes before beginning the } \\
\text { interventions) }\end{array}$ \\
\hline Goubet et al. [44] & N/A \\
\hline Gray et al. [45] & N/A \\
\hline Greenberg [46] & $\begin{array}{l}\text { Age, weight, time since last feeding, heel stick and blood collection procedure length, and } \\
\text { gestational age }\end{array}$ \\
\hline Grunau et al. [25] & Corrected chronological age \\
\hline Haouari et al. [47] & N/A \\
\hline Jatana et al. [48] & $\mathrm{N} / \mathrm{A}$ \\
\hline Johnston et al. [49] & $\begin{array}{l}\text { Apgar scores at } 5 \text { minutes, gestational age at birth, time since last painful procedure, number of } \\
\text { painful procedures since admission, or received indomethacin in the past } 12 \text { hours }\end{array}$ \\
\hline Johnston et al. [50] & Frequency of invasive procedures, severity of illness, ventilation status, and sex \\
\hline Kostandy et al. [51] & N/A \\
\hline Leite et al. [52] & $\mathrm{N} / \mathrm{A}$ \\
\hline Lindh et al. [55] & $\mathrm{N} / \mathrm{A}$ \\
\hline Lindh et al. [54] & $\mathrm{N} / \mathrm{A}$ \\
\hline Lindh et al. [53] & N/A \\
\hline Lucas-Thompson et al. [56] & Number of prior heel sticks, duration of blood draws, sex, and baseline heart rate \\
\hline Oberlander et al. [57] & $\begin{array}{l}\text { Breast-fed, SSRI exposure, age at time of acute pain, maternal analgesia, dose of SSRI at delivery, } \\
\text { and dose of clonazepam at time of delivery }\end{array}$ \\
\hline Oberlander et al. [58] & $\begin{array}{l}\text { Breast-fed, SSRI exposure, age at time of acute pain, maternal analgesia, dose of SSRI at delivery, } \\
\text { and dose of clonazepam at time of delivery }\end{array}$ \\
\hline Oberlander et al. [59] & $\mathrm{N} / \mathrm{A}$ \\
\hline Ors et al. [60] & $\mathrm{N} / \mathrm{A}$ \\
\hline Owens and Todt [61] & Sex \\
\hline Sajedi et al. [62] & Sex \\
\hline Shibata et al. [63] & $\mathrm{N} / \mathrm{A}$ \\
\hline Singh et al. [27] & $\mathrm{N} / \mathrm{A}$ \\
\hline Stevens et al. [65] & $\mathrm{N} / \mathrm{A}$ \\
\hline Stevens and Johnston [64] & $\mathrm{N} / \mathrm{A}$ \\
\hline Taksande et al. [66] & $\mathrm{N} / \mathrm{A}$ \\
\hline Upadhyay et al. [67] & N/A \\
\hline Uyan et al. [68] & N/A \\
\hline Walden et al. [69] & N/A \\
\hline Weissman et al. [70] & N/A \\
\hline Weissman et al. [71] & N/A \\
\hline
\end{tabular}

Note. $\mathrm{N} / \mathrm{A}=$ not applicable. 
TABLE 3: Mean and standard deviations for heart rate response to acute pain at less than 7 postnatal days.

\begin{tabular}{|c|c|c|c|}
\hline Gestational age & Reference & $\begin{array}{c}\text { Mean HR } \\
(\mathrm{bpm})\end{array}$ & SD \\
\hline 25-27 weeks & Craig et al. [24] & 172.38 & 17.22 \\
\hline \multirow{4}{*}{$28-32$ weeks } & Cong et al. [39] & 165.00 & 14.00 \\
\hline & Craig et al. [24] & 168.20 & 10.50 \\
\hline & Craig et al. [24] & 155.25 & 21.57 \\
\hline & Lucas-Thompson et al. [56] & 169.27 & 10.89 \\
\hline \multirow{4}{*}{ 32-34 weeks } & Singh et al. [27] & 183.40 & 15.93 \\
\hline & Stevens and Johnston [64] & 162.20 & 15.36 \\
\hline & Stevens et al. [65] & 154.00 & 13.00 \\
\hline & Lucas-Thompson et al. [56] & 158.18 & 15.19 \\
\hline \multirow{2}{*}{ 34-37 weeks } & Craig et al. [24] & 163.20 & 27.82 \\
\hline & Singh et al. [27] & 165.30 & 16.50 \\
\hline \multirow{11}{*}{ 37-42 weeks } & Abad et al. ${ }^{*}[34]$ & 170.00 & N/A \\
\hline & Craig et al. [24] & 145.86 & 19.22 \\
\hline & Campos [38] & 174.00 & 16.60 \\
\hline & Gormally et al. ${ }^{*}$ [43] & 180.00 & N/A \\
\hline & Gray et al. ${ }^{*}$ [45] & 123.00 & $\mathrm{~N} / \mathrm{A}$ \\
\hline & Kostandy et al. ${ }^{*}[51]$ & 155.00 & $\mathrm{~N} / \mathrm{A}$ \\
\hline & Leite et al. [52] & 172.70 & 21.50 \\
\hline & Lindh et al. [55] & 134.00 & 19.00 \\
\hline & Lindh et al. [54] & 144.00 & 20.00 \\
\hline & Oberlander et al. ${ }^{*}$ [57] & 168.00 & N/A \\
\hline & Shibata et al. ${ }^{*}[63]$ & 170.00 & N/A \\
\hline
\end{tabular}

Note. $*$ denotes numbers that were extrapolated from graphs.

\subsubsection{Age at Measurement: Seven Postnatal Days or Less}

Extremely Preterm: 25 to 27 Weeks of GA

Mean Heart Rate. One high quality study used mean HR to describe the acute pain experience following a heel stick in those born at 25-27 weeks of GA and were measured at 5.50 postnatal days [24]. The authors found that those born at 2527 weeks of GA did not have a significant increase in mean HR in response to a heel stick in the first week of life. The study found that the mean HR was $172.38 \mathrm{bpm}$ in response to heel stick.

\section{Very Preterm: 28 to 32 Weeks of $G A$}

Mean Heart Rate. A total of 3 studies investigated the mean HR response to heel stick in those born at 28 to 32 weeks of GA and measured at 3 to 6 postnatal days $[24,39,56]$. The three studies found that HR significantly increased following the heel stick $[24,39,56]$. The studies found that mean HR postacute pain ranged from 155.25 to 169.27 bpm (see Table 3 ). The variability may be due to only one study including covariates (i.e., number of prior heel sticks, duration of blood draws, sex, and baseline HR) in their analysis of the cardiovascular measures [73]. Overall, the studies were generally of high quality.
Heart Rate Change. One lower quality study examined mean HR change in response to heel stick at 4 postnatal days [44] and found that HR was significantly higher during blood collection compared to baseline HR (see Table 4).

Heart Rate Variability. One high quality study investigated LF and HF HRV, as well as the LF/HF ratio in response to heel stick at 6 postnatal days [39]. The authors found that LF and HF HRV increased in response to heel stick (see Tables 5 and 6 , resp.), while the $\mathrm{LF} / \mathrm{HF}$ ratio decreased in response to heel stick (see Table 7).

\section{Moderate Preterm: 32 to 34 Weeks GA}

Mean Heart Rate. A total of 4 studies investigated the mean $\mathrm{HR}$ response to heel stick [14, 26, 51, 65], while 1 study investigated the mean $\mathrm{HR}$ response to venipuncture [21]. All studies investigated infants between 3 and 7 postnatal days. Overall, mean HR was found to increase in response to acute pain. However, the magnitude of responses was variable and ranged from 154 to $183.4 \mathrm{bpm}$, with mean HR being higher in the study using venipuncture as the acutely painful stimulus. Additionally, variability in the magnitude of mean HR response may be due to the fact that over half of the studies are not including covariates in their analysis $[14,27,65]$. In the two studies that did include covariates, the authors controlled for the frequency of invasive procedures, severity of illness, ventilation status, sex, number of prior heel sticks, duration of blood draws, and baseline HR. Overall, the quality of the studies varied (i.e., $40 \%$ compared to $85 \%$ ).

Heart Rate Variability. One high quality study investigated mean total HRV in response to heel stick at 5 postnatal days or less [14]. It was found that total HRV was not significantly different in response to heel stick (see Table 8). However, total HRV represented the standard deviation of the mean HR, which may have affected the accuracy of the measure.

\section{Late Preterm: 34 to 37 Weeks of GA}

Mean Heart Rate. A total of 2 studies investigated mean HR response to heel stick [24] or venipuncture [27]. The studies investigated infants at 3 to 7 postnatal days. In both studies, mean HR increased following the acute pain procedure. Mean $\mathrm{HR}$ in response to acute pain was found to be 165.3 and $163.2 \mathrm{bpm}$ after heel stick and venipuncture, respectively. The quality of the studies was found to vary (i.e., $40 \%$ compared to $85 \%$ ).

\section{Full Term: 37 to 42 Weeks of GA}

Mean Heart Rate. A total of 9 studies investigated mean HR response to heel stick $[24,38,43,45,52,55,57,63,71], 4$ in response to venipuncture $[27,34,54,66]$, and 1 in response to vaccination [51]. The studies investigated infants at 0 to 7 postnatal days. Overall, mean HR increased after acute pain procedure; however, as in premature infants, the magnitude of the response was variable in term born infants. Mean HR ranged from 134 to $174 \mathrm{bpm}$ in response to acute pain. Out of the 14 studies investigating mean HR response to acute pain, 
TABLE 4: Mean and standard deviations for heart rate change from baseline in response to acute pain at less than 7 postnatal days.

\begin{tabular}{|c|c|c|c|}
\hline Gestational age & Reference & HR change & $\mathrm{SD}$ \\
\hline 28-32 weeks & Goubet et al. ${ }^{*}$ [44] & $0-15 \mathrm{bpm}$ & N/A \\
\hline \multirow{11}{*}{$37-42$ weeks } & Altun-Köroğlu et al. [35] & $37.00 \%$ & N/A \\
\hline & Bilgen et al. [36] & $19.00 \%$ & N/A \\
\hline & Bucher et al. $^{*}$ [37] & $45 \mathrm{bpm}$ & N/A \\
\hline & Gray et al. [45] & $36-38 \mathrm{bpm}$ & N/A \\
\hline & Haouari et al. [47] & $11.40 \%$ & 3.0 \\
\hline & Jatana et al. [48] & $31.48 \mathrm{bpm}$ & $6.66 \mathrm{bpm}$ \\
\hline & Ors et al. [60] & $19.00 \%$ & N/A \\
\hline & Owens and Todt [61] & $49.00 \mathrm{bpm}$ & $17.5 \mathrm{bpm}$ \\
\hline & Sajedi et al. [62] & 10.81 & N/A \\
\hline & Uyan et al. [68] & $38.20 \%$ & N/A \\
\hline & Weissman et al. [70] & $36.50 \mathrm{bpm}$ & $19.50 \mathrm{bpm}$ \\
\hline
\end{tabular}

Note. $*$ denotes numbers that were extrapolated from graphs.

TABLE 5: Mean and standard deviations for low frequency heart rate variability in response to acute pain at less than 7 postnatal days.

\begin{tabular}{lccr}
\hline Gestational age & Reference & Mean LF HRV & SD \\
\hline 28-32 weeks & Cong et al. [39] & 17.62 & 24.55 \\
\hline & Gormally et al. ${ }^{\text {[43] }}$ & 1.65 & N/A \\
$37-42$ weeks & Lindh et al. [55] & 4.2 & 0.4 \\
& Lindh et al. [54] & 4.00 & 0.39 \\
& Oberlander et al. ${ }^{\text {[5] }}$ & 11.0 & N/A \\
& Weissman et al. [71] & 1.45 & 0.38 \\
\hline
\end{tabular}

Note. $\mathrm{HRV}=$ heart rate variability, $\mathrm{LF}=$ low frequency, $\mathrm{SD}=$ standard deviation, and $*$ denotes numbers that were extrapolated from graphs.

TABLE 6: Mean and standard deviations for high frequency heart rate variability in response to acute pain at less than 7 postnatal days.

\begin{tabular}{lccr}
\hline Gestational age & Reference & Mean HF HRV & SD \\
\hline 28-32 weeks & Cong et al. [39] & 23.52 & 35.96 \\
\hline & de Oliveira et al. [42] & 0.44 & 0.69 \\
& Greenberg* [46] & 2.5 & N/A \\
$37-42$ weeks & Lindh et al. [55] & 3.4 & 0.60 \\
& Lindh et al. [54] & 3.23 & 0.45 \\
& Oberlander et al. ${ }^{*}$ [57] & 2.0 & N/A \\
& Weissman et al. [71] & 0.76 & 0.50 \\
\hline
\end{tabular}

Note. $\mathrm{HRV}=$ heart rate variability, $\mathrm{HF}=$ high frequency, $\mathrm{SD}=$ standard deviation, and $*$ denotes numbers that were extrapolated from graphs.

TABLE 7: Mean and standard deviations for low frequency/high frequency ratio in response to acute pain at less than 7 postnatal days.

\begin{tabular}{lccc}
\hline Gestational age & Reference & Mean LF/HF ratio & SD \\
\hline 28-32 weeks & Cong et al. [39] & 1.75 & 1.84 \\
\hline \multirow{2}{*}{ 37-42 weeks } & Oberlander et al. ${ }^{*}$ [57] & 6.00 & N/A \\
& Weissman et al. [71] & 6.1 & 3.2 \\
\hline
\end{tabular}

Note. $\mathrm{LF}=$ low frequency, $\mathrm{HF}=$ high frequency, $\mathrm{SD}=$ standard deviation, and * denotes numbers that were extrapolated from graphs.

only three included covariates in their analyses [38, 43, 57], which again may explain the variability in the results. These studies included the number of additional sticks required to
TABLE 8: Mean and standard deviations for total heart rate variability in response to acute pain at less than 7 postnatal days.

\begin{tabular}{lccc}
\hline Gestational age & Reference & $\begin{array}{c}\text { Mean total } \\
\text { HRV }\end{array}$ & SD \\
\hline 32-34 weeks & $\begin{array}{c}\text { Stevens and } \\
\text { Johnston [64] }\end{array}$ & 4.52 & 2.95 \\
\hline \multirow{2}{*}{ 37-42 weeks } & Lindh et al. [55] & 4.30 & 0.40 \\
& Lindh et al. [54] & 4.10 & 0.35 \\
\hline
\end{tabular}

Note. $\mathrm{HRV}=$ heart rate variability, $\mathrm{SD}=$ standard deviation.

obtain the blood sample, duration of the heel stick, frequency of crying, average $\mathrm{HR}$, preintervention baseline (percentage of time crying in the last two minutes before beginning the 
TABLE 9: Mean and standard deviations for maximum heart rate in response to acute pain at less than 7 postnatal days.

\begin{tabular}{lccc}
\hline Gestational age & Reference & $\begin{array}{c}\text { Maximum } \\
\text { HR (bpm) }\end{array}$ & SD \\
\hline \multirow{3}{*}{ 37-42 weeks } & Campos [38] & 192.00 & 11.80 \\
& de Jesus et al. [41] & 149.00 & N/A \\
& Owens and Todt [61] & 179.40 & 13.40 \\
& Singh et al. [27] & 160.30 & 20.00 \\
& Taksande et al. [66] & 151.00 & 10.40 \\
& Uyan et al. [68] & 186.00 & N/A \\
\hline
\end{tabular}

Note . bpm $=$ beats per minute, $\mathrm{HR}=$ heart rate, $\mathrm{SD}=$ standard deviation.

interventions), breast-fed (yes/no), SSRI exposure (yes/no), age at time of acute pain, maternal analgesia (yes/no), dose of SSRI at time of delivery, and dose of clonazepam at time of delivery. Overall, the quality of the studies was variable and ranged from low to high quality.

Maximum Heart Rate. A total of 6 studies investigated maximum $\mathrm{HR}$ while infants underwent a heel stick procedure at 2 to 7 postnatal days [35, 36, 38, 41,61, 68]. Overall, maximum HR was found to increase in response to the heel stick and ranged from 149 to $192 \mathrm{bpm}$ (Table 9). Two studies included covariates in their analysis [38, 41], which were number of additional sticks required to obtain the blood sample, duration of the heel stick, frequency of crying, average $\mathrm{HR}$, gestational age, birth weight, sex, mode of delivery, diabetic mother (yes/no), breast-fed one hour before puncture (yes/no), or received oral glucose (yes/no). Overall, the studies were relatively lower in quality (i.e., 60 to $75 \%$ ).

Heart Rate Change. A total of 9 studies investigated mean HR change in response to heel stick $[37,45,47,48,60,61,68,70]$ and intramuscular injection [62] from 0 to 7 postnatal days. In all studies, mean HR increased significantly in response to acute pain. Mean HR was found to increase by 31 to $49 \mathrm{bpm}$ or between 11 and 38 percent. Only three studies included covariates in their analysis of the cardiovascular [37, 61, 62], which included sex, nurse, number of lances needed, baseline $\mathrm{HR}$, and activity. The studies included were generally high in quality.

Heart Rate Variability. A total of 8 studies investigated mean HF HRV, 6 studies investigated LF HRV, and 3 studies investigated the LF/HF ratio or total HRV during heel stick $[42,43,46,54,57,70,71]$ or venipuncture [15]. Total HRV was found to be variable in the two studies, with one study suggesting its increase in response to heel stick [8] and the other study suggesting its decrease in response to venipuncture [15]. It is possible that the two acutely painful procedures may have differed in the amount of pain caused. There was also variability in HF HRV, with some studies finding HF HRV decreased in response to acute pain [42, 46, 57, 70,71], and some studies finding no difference in HF HRV in response to acute pain $[43,54,55]$. These differences in response patterns may be due in part to the heterogeneity of covariates included in four of the studies $[42,43,54,55]$ and the lack of covariates included in the four remaining studies [54, 55, 70,71]. LF HRV was found to decrease in response to acute pain in four studies $[54,57,70,71]$ and increase in one study [54]. Only one study included covariates in their analyses, which may help to explain the variability in the results [57]. Finally, the LF/HF ratio was found to increase in the three studies $[57,70,71]$, with only one study including covariates in the analysis [57]. These studies included infants between 0 and 7 postnatal days, and the studies ranged in quality from 50 to $80 \%$.

\section{Summary of Results: Age of Measurement Less Than 7 Postnatal Days}

Mean Heart Rate. The magnitude of cardiovascular response was variable across GAs, with those born at 25 to 27 weeks GA displaying a blunted $\mathrm{HR}$ response to acute pain, and those born at 28 to 42 weeks GA displaying an increase in HR across phases that increased in variability as GA increased.

Mean Heart Rate Change. Mean HR change was utilized in studies investigating infants born at 28 to 32 weeks and 37 to 42 weeks of GA. Both groups had a significant increase in HR following the acutely painful procedure. Maximum HR in response to a heel stick was utilized in infants' born at 37 to 42 weeks GA. All studies found that maximum HR increased in response to the heel stick.

Heart Rate Variability. Total HRV, LF HRV, HF HRV, and the $\mathrm{LF} / \mathrm{HF}$ ratio were examined in infants born at 28 to 32,32 to 34 , and 37 to 42 weeks of GA. Although LF and HF HRV were found to increase and the LF/HF ratio decreased in response to acute pain in one study investigating those born at 28 to 32 weeks GA, clear patterns of HRV in response to acute pain could not be deciphered in the later born infants (i.e., 32 to 34 and 37 to 42 weeks of GA).

3.2.2. Age at Measurement: One to Two Postnatal Weeks. No studies investigated cardiovascular responses to acute pain in extremely preterm infants in the first or second postnatal week of life.

\section{Very Preterm: 28 to 32 Weeks of GA}

Mean HR Change. One lower quality study investigated the mean change in HR following a heel stick at one postnatal week [44]. The authors found that infants' HR increased by approximately 5 to $10 \mathrm{bpm}$ during the most invasive event of the blood collection. One study investigated mean HR change following a heel stick procedure in infants who were less than 14 postnatal days old [40]. During the procedure the authors found that mean HR increased significantly from baseline to heel stick procedure, with a mean HR change of $22.40 \mathrm{bpm}$ and standard deviation of 15.42 .

Heart Rate Variability. One high quality study investigated several components of HRV in response to a heel stick at 14 postnatal days or less [40]. The authors reported that LF and 
HF HRV increased in response to heel stick, while the LF/HF ratio decreased in response to heel stick. At the time of heel stick, mean LF HRV was reported at 69.84, with a standard deviation of 102.08, mean HF HRV was reported at 24.04, with a standard deviation of 40.90 , and the LF/HF ratio was reported at 23.98, with a standard deviation of 21.39.

\section{Moderate to Late Preterm: 32 to 35 Weeks of GA}

Mean Heart Rate. One relatively high quality study investigated mean HR in response to a heel stick at less than 10 postnatal days [49]. Mean HR was found to increase in response to the heel stick and was approximately $159 \mathrm{bpm}$ in response to the acute pain. A variety of covariates were included in the analysis of the cardiovascular measure, which included Apgar scores at 5 minutes, GA at birth, time since last painful procedure, number of painful procedures since admission, or received indomethacin in the past 12 hours (yes/no).

\section{Full Term: 37 to 42 Weeks of GA}

Mean Heart Rate. Two studies investigated mean HR response to heel stick [24] or venipuncture [67] at less than 15 postnatal days old. Mean HR was found to significantly increase in response to venipuncture and was reported at $163 \mathrm{bpm}$ following the acutely painful procedure. In response to heel stick, mean HR was found to increase to $145.86 \mathrm{bpm}$ with a standard deviation of 19.22 [24]. Overall, the quality of the studies was high.

\section{Summary of Results: Age of Measurement One to Two} Postnatal Weeks

Mean Heart Rate. Data were available from studies investigating those born at 28 to 32,32 to 35 , and 37 to 42 weeks of GA during the second postnatal week. Mean HR significantly increased in response to acutely painful procedures. The magnitude of $\mathrm{HR}$ responses was variable within and across GA groups.

Heart Rate Variability. One study investigated infants born at 28 to 32 weeks GA and found that they have an increased LF and HF HRV and a decreased LF/HF ratio in response to acute pain.

3.2.3. Age at Measurement: Three Postnatal Weeks. No studies investigated cardiovascular responses to acute pain in very preterm, moderate to late preterm, or full term infants in the third postnatal week of life.

Extremely Preterm: 24 to 26 Weeks of GA. One high quality study investigated the mean and maximum HR response following a heel stick at 21 postnatal days [69]. The authors found that mean and maximum HR increased during the heel stick and were reported as $174.90 \mathrm{bpm}$ with a standard deviation of $9.86 \mathrm{bpm}$ and $175.91 \mathrm{bpm}$ with a standard deviation of $10.35 \mathrm{bpm}$, respectively.
Summary of Results: Age of Measurement at Three Postnatal Weeks

Mean Heart Rate. In extremely preterm infants, mean and maximum HR were found to increase in response to acute pain at 3 postnatal weeks old. The blunted HR response that was noted in the first seven postnatal days was not found, suggesting an increased response to acute pain developing in extremely preterm infants in the first three weeks of life.

3.2.4. Age at Measurement: One Postnatal Month. No studies investigated cardiovascular responses to acute pain in moderate to late preterm or full term infants in the third postnatal week of life.

\section{Extremely Preterm: 24 to 28 Weeks of GA}

Mean Heart Rate. Two studies with varying quality levels investigated mean HR following a heel stick procedure at four postnatal weeks $[26,59]$. The authors found that there were significant increases in mean HR following the heel stick. The approximate mean HR response following the heel stick ranged from 170 to $190 \mathrm{bpm}$. A variety of covariates were included in one analysis [26], which comprised frequency of invasive procedures, severity of illness, ventilation status, and sex.

Heart Rate Variability. One study investigated LF and HF HRV and the LF/HF ratio during a heel lance procedure [59]. LF and HF HRV as well as the LF/HF ratio decreased during heel lance and were approximately 5.0, 1.0, and 8.0 during the heel lance, respectively.

\section{Very Preterm: 28 to 32 Weeks of GA}

Mean Heart Rate. One high quality study investigated mean HR following a heel stick at three to five postnatal weeks [56]. The authors found that mean HR was significantly higher during the heel stick than during recovery and was reported at $175.94 \mathrm{bpm}$, with a standard deviation of $12.66 \mathrm{bpm}$ during the heel stick. The number of prior heel sticks, duration of blood draws, sex, and baseline HR were included as covariates in the analysis.

\section{Summary of Results: Age of Measurement at One Postnatal Month}

Mean Heart Rate. Data from studies investigating infants at 24 to 28 and 28 to 32 weeks GA were available. Both studies found that mean HR increased in response to acute pain. Mean HR at one postnatal month was higher in response to acute pain, as compared to the first 7 postnatal days in those born at 28 to 32 weeks of GA.

Heart Rate Variability. At one postnatal month, one study found that LF and HF HRV and the LF/HF ratio decreased in response to acute pain in infants born at 24 to 28 weeks of GA. 
3.2.5. Age at Measurement: Two Postnatal Months. No studies investigated cardiovascular responses to acute pain in extremely, very, or moderate to late preterm infants in the second postnatal month of life.

\section{Full Term: 37 to 42 Weeks of GA}

Mean Heart Rate. One relatively lower quality study investigated mean HR responses to a heel stick procedure at two postnatal months [57]. The authors found that mean HR increased after heel stick and was approximately $190 \mathrm{bpm}$ during the heel stick. The authors included a variety of covariates in their analysis (i.e., breast-fed (yes/no), SSRI exposure (yes/no), age at time of acute pain, maternal analgesia (yes/no), dose of SSRI at time of delivery, and dose of clonazepam at time of delivery).

Heart Rate Variability. The same study investigated mean HRV during the aforementioned acute pain procedure [57]. The authors found that, during the heel stick procedure, LF HRV and the LF/HF ratio decreased; however, there were no significant differences in HF HRV. HF and LF HRV and the LF/HF ratio were approximately 4.0, 28.0, and 8.0 during the heel stick procedure, respectively. The above-mentioned covariates were used in the analysis.

\section{Summary of Results: Two Postnatal Months}

Mean Heart Rate. One study investigated those born at 37 to 42 weeks GA. Mean HR was found to increase in response to acute pain.

Heart Rate Variability. Although LF HRV and the LF/HF ratio were found to decrease in response to pain, HF HRV was not significantly different from baseline to heel stick.

3.2.6. Age at Measurement: Three Postnatal Months. No studies investigated cardiovascular responses to acute medical procedure pain in extremely preterm, very preterm, or moderate to late preterm infants in the third postnatal month of life.

\section{Full Term: 37 to 42 Weeks GA}

Mean Heart Rate. One relatively lower quality study investigated mean HR response following a heel stick at three postnatal months [53]. Mean HR increased after heel stick and was approximately $169 \mathrm{bpm}$ during this time.

Heart Rate Variability. The same study investigated mean HRV during the aforementioned heel stick procedure [53]. In the study, the authors found that total HRV and the LF HRV increased during the heel stick; however there were no significant differences in HF HRV compared to baseline. When extrapolating the values, total HRV, HF, and LF HRV were approximately $4.10,3.20$, and 4.0 during the heel stick procedure, respectively.
Summary of Results: Age of Measurement at Three Postnatal Months

Mean Heart Rate. Data from one lower quality study investigating those born at 37 to 42 weeks GA were available. Mean $\mathrm{HR}$ was found to increase in response to acute pain.

Heart Rate Variability. Although total and LF HRV were found to increase in response to pain, HF HRV was not significantly different from baseline to heel stick.

3.2.7. Age at Measurement: Four Postnatal Months. No studies investigated cardiovascular responses to acute pain in moderate to late preterm infants in the third postnatal week of life.

Extremely Preterm: 24 to 28 Weeks of GA

Mean Heart Rate. One relatively higher quality study investigated mean HR response following immunizations at four postnatal months [25]. The authors found that mean HR changed significantly across events, with significant increases from the end of baseline to first injection and from first injection to third injection. The approximate mean HR during the immunizations was $185 \mathrm{bpm}$. Corrected chronological age was included as a covariate in the analysis.

Very Preterm: 28 to 32 Weeks of GA

Mean Heart Rate. The same study investigated mean HR response following immunizations at four postnatal months in infants born at 29 to 32 weeks of GA [25]. The authors found that mean HR changed significantly across events, with significant increases from the end of baseline to first injection and from first injection to third injection. The approximate mean HR during the immunizations was $188 \mathrm{bpm}$. The abovementioned covariate was included in the analysis.

Full Term: 37 to 42 Weeks of GA

Mean Heart Rate. One study investigated mean HR response following immunizations at four postnatal months in infants born at 38 to 41 weeks of GA [25]. The authors found that mean HR changed significantly across events, with significant increases from the end of baseline to first injection and from first injection to third injection. The approximate mean $\mathrm{HR}$ during the immunizations was $182 \mathrm{bpm}$. The abovementioned covariate was included in the analysis.

Summary of Results: Age of Measurement at Four Postnatal Months. Only one cross-sectional, relatively higher quality study [25] investigated the effect of GA on mean HR response following immunizations. The authors found that mean $\mathrm{HR}$ increased in response to acute pain in all GA groups. However, there was no effect of GA group (i.e., 24-28, 29-32, and 38-41 weeks GA) on mean HR response.

\section{Discussion}

To our knowledge, this is the first systematic review investigating the development of cardiovascular indices of acute 
pain responding across the first year of life. Large gaps were elucidated in this review and suggest that the development of infant pain responding outside of the first month of life still remains largely unknown. By way of overview, when measuring HR in the first 7 days of life, the variability within each age group on these measures became larger as the infant's GA increased. Measures of HRV in the first 7 days of life seemed to show less variability within age categories as the child's GA increased. Data from other postnatal age groups (i.e., 2nd week, 3rd week, 1 month, 2 months, 3 months, and 4 months) were very sparse with patterns generally impossible to discern due to the total absence or presence of only 1 study.

The following paragraphs will discuss key findings and patterns in the results of the systematic review with specific attention to GA at birth, age at measurement, and type of cardiac measurement in response to acutely painful procedures. Limitations and review contributions to the literature, as well as key areas for future research based on the findings, will be highlighted.

4.1. Extremely Preterm. Those born at less than 28 weeks GA displayed a blunted HR response to acute pain in the first week of life. At three weeks, as well as one and four postnatal months, mean HR was found to significantly increase during acutely painful procedures, as compared to baseline HR. Mean HR was higher at four postnatal months than during the first postnatal month. This synthesis suggests that mean HR responses to acute pain may stabilize developmentally (i.e., to increase in response to a stressor as in older humans) in extremely preterm infants after the first postnatal week of life. At one postnatal month of life, LF and HF HRV and the $\mathrm{LF} / \mathrm{HF}$ ratio decreased in response to acute pain.

Past research has noted a blunted pain response in the first week of life based on GA [74-76]. It is possible that the health status of the child at birth may affect the infants' ability to react to invasive procedures during the first week of life [77]. The increase in cardiac responding from the first to the fourth postnatal months of life suggests that extremely low GA infants begin to demonstrate increased physiological responses to acute pain as the cardiovascular system matures [74-76]. Although the relative quality of studies was good (76 to $86 \%$ ), it is important to interpret this qualitative synthesis with caution, given the relatively small group of studies $(N=$ 3 ) and the lack of covariates in two of the three studies.

4.2. Very Preterm. In infants born between 28 and less than 32 weeks GA, mean HR was found to significantly increase following an acutely painful procedure from birth to four months of age. Mean HR was found to be higher at four months compared to one to two postnatal weeks of life. As mentioned above with extremely preterm infants, this increase in mean HR is likely linked to an increase in the parasympathetic contribution to HR control [74-76].

Although HRV components were only investigated in one study of very preterm infants in the second postnatal week of life, LF and HF HRV were found to increase, while the $\mathrm{LF} / \mathrm{HF}$ ratio decreased in response to acute pain. Caution should be taken when interpreting these HR and HRV results, as it is based on four studies (quality scores range from 62 to $85 \%$ ) and a single study (quality score: $85 \%$ ), respectively. Additionally, only one study included covariates in their analysis.

4.3. Moderate to Late Preterm. In infants born at 32 to less than 37 weeks GA, mean HR was found to increase in response to acute pain during the first postnatal week of life; however, the magnitude of responses was variable. Mean HR was found to be stable across the second week of life and increased in response to acute pain. The inconsistencies in mean HR may be due to differences in the acute pain procedure (i.e., heel stick versus venipuncture), the variability in quality of studies (40 to $85 \%$ ), and the lack of covariates included in the analyses of more than half of the studies (3/5).

Additionally, when total HRV in response to acute pain was examined in the first week of life in those born at 32 to 34 weeks GA, it did not significantly differ from baseline HRV. This may be due to nonlinearity in heartbeats, which is necessary to measure HRV, being less apparent before 35 weeks GA [76]. Moreover, the conclusions are based on one study with adequate quality (75\%), and there were no covariates included in the analysis.

4.4. Full Term. During the first four postnatal months of life, full term infants displayed an increase in mean HR in response to acute pain; however, the magnitude of responses was variable. A relative increase in mean $H R$ over the first four postnatal months was noted and may reflect a developmental, relative increase in the parasympathetic contribution to $\mathrm{HR}$ control [75]. Conversely, the variability in results may be due to the following: the lack of studies per age group at two, three, and four postnatal months, the study authors including differing or no covariates in their analyses, and the variable quality of studies.

During the first postnatal week of life, total, LF, and HF $\mathrm{HRV}$ in response to acute pain were found to be inconsistent among full term infants. The LF/HF ratio was the only consistent measure of HRV, and it was found to decrease in response to acute pain across studies. At two postnatal months, LF HRV and the LF/HF ratio decreased in response to acute pain. At three months of age in response to acute pain, total and LF HRV increased. There were no differences in HF HRV when compared to baseline levels at two or three postnatal months.

As mentioned above, the inconsistency within the HRV domains may be explained by the linear statistics utilized by authors [76]. As well, only one study out of eight included covariates in their analysis, and the quality of the studies varied qualitatively (55 to $80 \%$ ).

4.5. Limitations of This Review. It is possible that we have omitted relevant studies despite our detailed search strategy, and we specifically excluded non-English language studies. Additionally, group-specific data (i.e., age at measurement and GA) were separated based on available data and natural groupings, which on occasion led to overlap in GA groups.

With regard to analyzing HRV, studies differed on spectrum calculation methods and models of data analysis. Although terminology such as LF and HF bands is common 
in the field, studies differ on frequency limits of the bands. Other studies utilized linear statistical approaches of comparing means and variance, which has been reported as less sensitive in classifying HRV in infants [75].

Furthermore, it was difficult to draw conclusions across development and GA groups for cardiovascular responses to acute medical procedure pain, as the majority of studies did not include covariates in their analyses that could impact an infants' cardiovascular response to acute pain. It is important to keep in mind that the variability in mean HR and HRV components may be due to this lack of control within the studies.

4.6. Implications for Research and Clinical Practice. The presence of variability in HR in older preterm infants and full term infants presents an important clinical challenge to gold-standard measures such as the PIPP-R, N-PASS, COMFORT, and Bernese Pain Scale. For example, the PIPP-R has physiological items (i.e., HR) that are numerically scored on a four-point scale reflecting changes in each variable from baseline values [19]. Given that natural variability in HR responding exists across all GA groups, it is possible that infants with more naturally reactive heart rates, and not higher subjective pain, may have higher scores on this pain scale. This may lead to infants receiving unnecessary pharmacological pain relief. Future research and clinical practice should address this concern in order to provide appropriate pain management to these vulnerable infants.

A lack of control within the studies investigated has been highlighted, with only 13 out of 41 studies including covariates in their analyses. Moreover, the covariates utilized in the studies are divergent, which may have increased the amount of variability noted in the cardiovascular responses to acute pain. Future research in the area of infant pain should address this lack of control by identifying and controlling for factors that may affect an infants' cardiovascular response to acute pain in their own research. Examining the studies that did use covariates, key covariates that should seriously be considered for inclusion in all cardiac response to pain studies (depending on design) are gestational age, age at measurement (i.e., postnatal age, corrected chronological age), birth weight, time since last feeding, ventilation status, baseline (i.e., prehandling cardiac responding), length of painful procedure, number of painful procedures (e.g., how many draw attempts), illness severity, sex, and respiration rate.

\section{Additional Points}

To our knowledge, this is the first systematic review of cardiac responding to acute pain within infancy. Forty-one studies were included to examine different methods of cardiac responses within developmentally sensitive categories. In response to acutely painful procedures, most infants had an increase in mean heart rate; however the magnitude of the increase showed great variability. Research in the area of heart rate variability was inconsistent limiting interpretation of studies using this measure. More attention to covariates and agreement on methodological factors related to cardiac measurement is needed to better understand this physiological response to pain.

\section{Disclosure}

Jordana A. Waxman is a trainee member of Pain In Child Health (PICH), a strategic research training initiative of the Canadian Institutes of Health Research.

\section{Competing Interests}

The authors had no conflict of interests to disclose.

\section{Acknowledgments}

This research was funded by salary and operating and infrastructure awards from the Canada Foundation for Innovation, Canadian Institutes for Health Research, and the Ontario Ministry of Research and Innovation awarded to Rebecca R. Pillai Riddell and awards to Jordana A. Waxman from the Lillian Wright Maternal Child Health Scholarship Program and Ontario Graduate Scholarship.

\section{References}

[1] E. N. Rodkey and R. P. Riddell, "The infancy of infant pain research: the experimental origins of infant pain denial," Journal of Pain, vol. 14, no. 4, pp. 338-350, 2013.

[2] F. Schwaller and M. Fitzgerald, "The consequences of pain in early life: injury-induced plasticity in developing pain pathways," European Journal of Neuroscience, vol. 39, no. 3, pp. 344352, 2014.

[3] B. Ambuel, K. W. Hamlett, C. M. Marx, and J. L. Blumer, "Assessing distress in pediatric intensive care environments: the COMFORT scale," Journal of Pediatric Psychology, vol. 17, no. 1, pp. 95-109, 1992.

[4] F. Denk, S. B. McMahon, and I. Tracey, "Pain vulnerability: a neurobiological perspective," Nature Neuroscience, vol. 17, no. 2, pp. 192-200, 2014.

[5] R. Grunau, "Long-term effects of pain in children," in Oxford Textbook of Paediatric Pain, P. McGrath, B. Stevens, S. Walker, and S. Zempsky, Eds., pp. 30-38, Oxford University Press, Oxford, UK, 2013.

[6] S. Brummelte, R. E. Grunau, V. Chau et al., "Procedural pain and brain development in premature newborns," Annals of Neurology, vol. 71, no. 3, pp. 385-396, 2012.

[7] R. E. Grunau, M. F. Whitfield, J. Petrie-Thomas et al., "Neonatal pain, parenting stress and interaction, in relation to cognitive and motor development at 8 and 18 months in preterm infants," Pain, vol. 143, no. 1-2, pp. 138-146, 2009.

[8] M. Ranger, C. M. Y. Chau, A. Garg et al., "Neonatal pain-related stress predicts cortical thickness at age 7 years in children born very preterm," PLoS ONE, vol. 8, no. 10, Article ID e76702, 2013.

[9] B. O. Valeri, L. Holsti, and M. B. M. Linhares, "Neonatal pain and developmental outcomes in children born preterm: a systematic review," The Clinical Journal of Pain, vol. 31, no. 4, pp. 355-362, 2015.

[10] J. Vinall, R. E. Grunau, R. Brant et al., "Slower postnatal growth is associated with delayed cerebral cortical maturation in preterm newborns," Science Translational Medicine, vol. 5, no. 168, p. 168ra8, 2013. 
[11] J. Vinall, S. P. Miller, B. H. Bjornson et al., "Invasive procedures in preterm children: brain and cognitive development at school age," Pediatrics, vol. 133, no. 3, pp. 412-421, 2014.

[12] I. A. Rouzan, "An analysis of research and clinical practice in neonatal pain management," Journal of the American Academy of Nurse Practitioners, vol. 13, no. 2, pp. 57-60, 2001.

[13] R. Slater, A. Cantarella, L. Franck, J. Meek, and M. Fitzgerald, "How well do clinical pain assessment tools reflect pain in infants?" PLoS Medicine, vol. 5, no. 6, article e129, 2008.

[14] R. Slater, L. Cornelissen, L. Fabrizi et al., "Oral sucrose as an analgesic drug for procedural pain in newborn infants: a randomised controlled trial," The Lancet, vol. 376, no. 9748, pp. 1225-1232, 2010.

[15] R. P. Riddell, D. B. Flora, S. A. Stevens et al., "Variability in infant acute pain responding meaningfully obscured by averaging pain responses," Pain, vol. 154, no. 5, pp. 714-721, 2013.

[16] L. G. Maxwell, C. P. Malavolta, and M. V. Fraga, "Assessment of pain in the neonate," Clinics in Perinatology, vol. 40, no. 3, pp. 457-469, 2013.

[17] R. E. Grunau, L. Holsti, and J. W. B. Peters, "Long-term consequences of pain in human neonates," Seminars in Fetal and Neonatal Medicine, vol. 11, no. 4, pp. 268-275, 2006.

[18] E. Cignacco, R. Mueller, J. P. H. Hamers, and P. Gessler, "Pain assessment in the neonate using the Bernese Pain Scale for Neonates," Early Human Development, vol. 78, no. 2, pp. 125131, 2004.

[19] S. Gibbins, B. J. Stevens, J. Yamada et al., "Validation of the Premature Infant Pain Profile-Revised (PIPP-R)," Early Human Development, vol. 90, no. 4, pp. 189-193, 2014.

[20] P. Hummel, P. Lawlor-Klean, and M. G. Weiss, "Validity and reliability of the N-PASS assessment tool with acute pain," Journal of Perinatology, vol. 30, no. 7, pp. 474-478, 2010.

[21] B. J. Stevens, S. Gibbins, J. Yamada et al., "The premature infant pain profile-revised (PIPP-R): initial validation and feasibility," The Clinical Journal of Pain, vol. 30, no. 3, pp. 238-243, 2014.

[22] B. Stevens, C. Johnston, P. Petryshen, and A. Taddio, "Premature infant pain profile: development and initial validation," Clinical Journal of Pain, vol. 12, no. 1, pp. 13-22, 1996.

[23] M. Van Dijk, J. B. De Boer, H. M. Koot, D. Tibboel, J. Passchier, and H. J. Duivenvoorden, "The reliability and validity of the COMFORT scale as a postoperative pain instrument in 0 to 3year-old infants," Pain, vol. 84, no. 2-3, pp. 367-377, 2000.

[24] K. Craig, M. F. Whitfield, R. V. E. Grunau, J. Linton, and H. D. Hadjistavropoulos, "Pain in the preterm neonate: behavioural and physiological indices," Pain, vol. 52, no. 3, pp. 287-299, 1993.

[25] R. E. Grunau, M. T. Tu, M. F. Whitfield et al., "Cortisol, behavior, and heart rate reactivity to immunization pain at 4 months corrected age in infants born very preterm," The Clinical Journal of Pain, vol. 26, no. 8, pp. 698-704, 2010.

[26] C. C. Johnston and B. J. Stevens, "Experience in a neonatal intensive care unit affects pain response," Pediatrircs, vol. 98, no. 5, pp. 925-930, 1996.

[27] H. Singh, D. Singh, and R. K. Soni, "Comparison of pain response to venipuncture between term and preterm neonates," Indian Pediatrics, vol. 37, no. 2, pp. 179-181, 2000.

[28] H. Bouza, "The impact of pain in the immature brain," The Journal of Maternal-Fetal and Neonatal Medicine, vol. 22, no. 9, pp. 722-732, 2009.

[29] P. M. Faye, J. De Jonckheere, R. Logier et al., "Newborn infant pain assessment using heart rate variability analysis," The Clinical Journal of Pain, vol. 26, no. 9, pp. 777-782, 2010.
[30] D. Moher, A. Liberati, J. Tetzlaff, and D. G. Altman, "Preferred reporting items for systematic reviews and meta-analyses: the PRISMA statement," Annals of Internal Medicine, vol. 151, no. 4, pp. 264-269, 2009.

[31] S. Sanderson, I. D. Tatt, and J. P. T. Higgins, “Tools for assessing quality and susceptibility to bias in observational studies in epidemiology: a systematic review and annotated bibliography," International Journal of Epidemiology, vol. 36, no. 3, pp. 666676, 2007.

[32] S. H. Downs and N. Black, "The feasibility of creating a checklist for the assessment of the methodological quality both of randomised and non-randomised studies of health care interventions," Journal of Epidemiology and Community Health, vol. 52, no. 6, pp. 377-384, 1998.

[33] I. K. Crombie and H. J. McQuay, “The systematic review: a good guide rather than a guarantee," Pain, vol. 76, no. 1-2, pp. 1-2, 1998.

[34] F. Abad, N. M. Díaz-Gómez, E. Domenech, D. González, M. Robayna, and M. Feria, "Oral sucrose compares favourably with lidocaine-prilocaine cream for pain relief during venepuncture in neonates," Acta Paediatrica, International Journal of Paediatrics, vol. 90, no. 2, pp. 160-165, 2001.

[35] Ö. Altun-Köroğlu, E. Özek, H. Bilgen, and D. Cebeci, "Hindmilk for procedural pain in term neonates," Turkish Journal of Pediatrics, vol. 52, no. 6, pp. 623-629, 2010.

[36] H. Bilgen, E. Özek, D. Cebeci, and R. Örs, "Comparison of sucrose, expressed breast milk, and breast-feeding on the neonatal response to heel prick," The Journal of Pain, vol. 2, no. 5, pp. 301-305, 2001.

[37] H. U. Bucher, R. Baumgartner, N. Bucher, M. Seiler, and J. C. Fauchère, "Artificial sweetener reduces nociceptive reaction in term newborn infants," Early Human Development, vol. 59, no. 1, pp. 51-60, 2000.

[38] R. G. Campos, "Rocking and pacifiers: two comforting interventions for heelstick pain," Research in Nursing \& Health, vol. 17, no. 5, pp. 321-331, 1994.

[39] X. Cong, S. M. Ludington-Hoe, G. McCain, and P. Fu, "Kangaroo care modifies preterm infant heart rate variability in response to heel stick pain: pilot study," Early Human Development, vol. 85, no. 9, pp. 561-567, 2009.

[40] X. Cong, R. M. Cusson, S. Walsh, N. Hussain, S. M. LudingtonHoe, and D. Zhang, "Effects of skin-to-skin contact on autonomic pain responses in preterm infants," The Journal of Pain, vol. 13, no. 7, pp. 636-645, 2012.

[41] J. A. de Jesus, R. M. Tristao, H. Storm, A. F. da Rocha, and D. J. Campos, "Heart rate, oxygen saturation, and skin conductance: a comparison study of acute pain in Brazilian newborns," in Proceedings of the Annual International Conference of the IEEE Engineering in Medicine and Biology Society (EMBC '11), pp. 1875-1879, Boston, Mass, USA, August-September 2011.

[42] M. V. M. de Oliveira, J. A. L. de Jesus, and R. M. Tristao, "Psychophysical parameters of a multidimensional pain scale in newborns," Physiological Measurement, vol. 33, no. 1, pp. 39-49, 2012.

[43] S. Gormally, R. G. Barr, L. Wertheim, R. Alkawaf, N. Calinoiu, and S. N. Young, "Contact and nutrient caregiving effects on newborn infant pain responses," Developmental Medicine and Child Neurology, vol. 43, no. 1, pp. 28-38, 2001.

[44] N. Goubet, R. K. Clifton, and B. Shah, "Learning about pain in preterm newborns," Journal of Developmental \& Behavioral Pediatrics, vol. 22, no. 6, pp. 418-424, 2001. 
[45] L. Gray, L. Watt, and E. M. Blass, "Skin-to-skin contact is analgesic in healthy newborns," Pediatrics, vol. 105, article e14, 2000.

[46] C. S. Greenberg, "A sugar-coated pacifier reduces procedural pain in newborns.," Pediatric nursing, vol. 28, no. 3, pp. 271-277, 2002.

[47] N. Haouari, C. Wood, G. Griffiths, and M. Levene, "The analgesic effect of sucrose in full term infants: a randomised controlled trial," British Medical Journal, vol. 310, no. 6993, pp. 1498-1500, 1995.

[48] S. K. Jatana, S. S. Dalal, and C. G. Wilson, "Analgesic effect of oral glucose in neonates," Medical Journal Armed Forces India, vol. 59, no. 2, pp. 100-104, 2003.

[49] C. C. Johnston, F. Filion, and A. M. Nuyt, "Recorded maternal voice for preterm neonates undergoing heel lance," Advances in Neonatal Care, vol. 7, no. 5, pp. 258-266, 2007.

[50] C. C. Johnston, B. Stevens, F. Yang, and L. Horton, "Developmental changes in response to heelstick in preterm infants: a prospective cohort study," Developmental Medicine and Child Neurology, vol. 38, no. 5, pp. 438-445, 1996.

[51] R. Kostandy, G. C. Anderson, and M. Good, "Skin-to-skin contact diminishes pain from Hepatitis B vaccine injection in healthy full-term neonates," Neonatal Network, vol. 32, no. 4, pp. 274-280, 2013.

[52] A. M. Leite, M. B. M. Linhares, J. Lander, T. C. Castral, C. B. dos Santos, and C. G. S. Scochi, "Effects of breastfeeding on pain relief in full-term newborns," Clinical Journal of Pain, vol. 25, no. 9, pp. 827-832, 2009.

[53] V. Lindh, U. Wiklund, H. K. Blomquist, and S. Håkansson, "EMLA ${ }^{\circledR}$ cream and oral glucose for immunization pain in 3month-old infants," Pain, vol. 104, no. 1-2, pp. 381-388, 2003.

[54] V. Lindh, U. Wiklund, and S. Håkansson, "Assessment of the effect of $\mathrm{EMLA}^{\circledR}$ during venipuncture in the newborn by analysis of heart rate variability," Pain, vol. 86, no. 3, pp. 247$254,2000$.

[55] V. Lindh, U. Wiklund, and S. Håkansson, "Heel lancing in term new-born infants: an evaluation of pain by frequency domain analysis of heart rate variability," Pain, vol. 80, no. 1-2, pp. 143148, 1999.

[56] R. Lucas-Thompson, E. L. Townsend, M. R. Gunnar et al., "Developmental changes in the responses of preterm infants to a painful stressor," Infant Behavior and Development, vol. 31, no. 4, pp. 614-623, 2008.

[57] T. F. Oberlander, R. E. Grunau, C. Fitzgerald et al., "Prolonged prenatal psychotropic medication exposure alters neonatal acute pain response," Pediatric Research, vol. 51, no. 4, pp. 443453, 2002.

[58] T. F. Oberlander, R. E. Grunau, C. Fitzgerald, M. Papsdorf, D. Rurak, and W. Riggs, "Pain reactivity in 2-month-old infants after prenatal and postnatal selective serotonin reuptake inhibitor medication exposure," Pediatrics, vol. 115, no. 2, pp. 411-425, 2005.

[59] T. F. Oberlander, R. E. Grunau, C. Fitzgerald, and M. F. Whitfield, "Does parenchymal brain injury affect biobehavioral pain responses in very low birth weight infants at 32 weeks' postconceptional age?” Pediatrics, vol. 110, no. 3, pp. 570-576, 2002.

[60] R. Ors, E. Ozek, G. Baysoy et al., "Comparison of sucrose and human milk on pain response in newborns," European Journal of Pediatrics, vol. 158, no. 1, pp. 63-66, 1999.

[61] M. E. Owens and E. H. Todt, "Pain in infancy: neonatal reaction to a heel lance," Pain, vol. 20, no. 1, pp. 77-86, 1984.
[62] F. Sajedi, Z. Kashaninia, M. Rahgozar, and L. Radrazm, "The efficacy of oral glucose for relieving pain following intramuscular injection in term neonates," Acta Medica Iranica, vol. 44, no. 5, pp. 316-322, 2006.

[63] M. Shibata, M. Kawai, T. Matsukura, T. Heike, K. Okanoya, and M. Myowa-Yamakoshi, "Salivary biomarkers are not suitable for pain assessment in newborns," Early Human Development, vol. 89, no. 7, pp. 503-506, 2013.

[64] B. J. Stevens and C. C. Johnston, "Physiological responses of premature infants to a painful stimulus," Nursing Research, vol. 43, no. 4, pp. 226-231, 1994.

[65] B. J. Stevens, C. C. Johnson, and L. Horton, "Multidimensional pain assessment in premature neonates: a pilot study," Journal of Obstetric, Gynecologic, \& Neonatal Nursing, vol. 22, no. 6, pp. 531-541, 1993.

[66] A. M. Taksande, K. Y. Vilhekar, M. Jain, and D. Chitre, "Pain response of neonates to venipuncture," Indian Journal of Pediatrics, vol. 72, no. 9, pp. 751-753, 2005.

[67] A. Upadhyay, R. Aggarwal, S. Narayan, M. Joshi, V. K. Paul, and A. K. Deorari, "Analgesic effect of expressed breast milk in procedural pain in term neonates: a randomized, placebocontrolled, double-blind trial," Acta Paediatrica, vol. 93, no. 4, pp. 518-522, 2004.

[68] Z. S. Uyan, E. Özek, H. Bilgen, D. Cebeci, and I. Akman, "Effect of foremilk and hindmilk on simple procedural pain in newborns," Pediatrics International, vol. 47, no. 3, pp. 252-257, 2005.

[69] M. Walden, J. H. Penticuff, B. Stevens et al., "Maturational changes in physiologic and behavioral responses of preterm neonates to pain," Advances in Neonatal Care, vol. 1, no. 12, pp. 94-106, 2001.

[70] A. Weissman, M. Aranovitch, S. Blazer, and E. Z. Zimmer, "Heel-lancing in newborns: behavioral and spectral analysis assessment of pain control methods," Pediatrics, vol. 124, no. 5, pp. e921-e926, 2009.

[71] A. Weissman, E. Z. Zimmer, M. Aranovitch, and S. Blazer, "Heart rate dynamics during acute pain in newborns," Pflügers Archiv, vol. 464, no. 6, pp. 593-599, 2012.

[72] H. Blencowe, S. Cousens, M. Z. Oestergaard et al., "National, regional, and worldwide estimates of preterm birth rates in the year 2010 with time trends since 1990 for selected countries: a systematic analysis and implications," The Lancet, vol. 379, no. 9832, pp. 2162-2172, 2012.

[73] A. Mitchell, S. Brooks, and D. Roane, "The premature infant and painful procedures," Pain Management Nursing, vol. 1, no. 2, pp. 58-65, 2000.

[74] W. C. Allan and D. B. Sobel, “The sans of time," The Journal of the American Medical Association, vol. 268, no. 8, p. 984, 1992.

[75] U. Chatow, S. Davidson, B. L. Reichman, and S. Akselrod, "Development and maturation of the autonomic nervous system in premature and full-term infants using spectral analysis of heart rate fluctuations," Pediatric Research, vol. 37, no. 3, pp. 294-302, 1995.

[76] G. Sugihara, W. Allan, D. Sobel, and K. D. Allan, "Nonlinear control of heart rate variability in human infants," Proceedings of the National Academy of Sciences of the United States of America, vol. 93, no. 6, pp. 2608-2613, 1996.

[77] V. Glover, R. Miles, S. Matta, N. Modi, and J. Stevenson, "Glucocorticoid exposure in preterm babies predicts saliva cortisol response to immunization at 4 months," Pediatric Research, vol. 58, no. 6, pp. 1233-1237, 2005. 


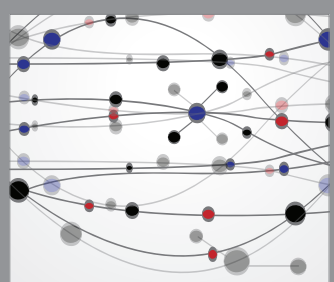

The Scientific World Journal
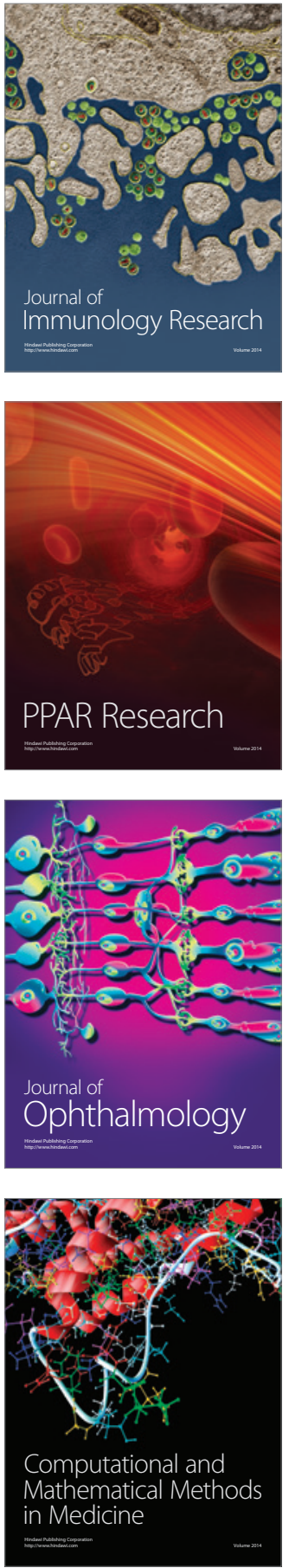

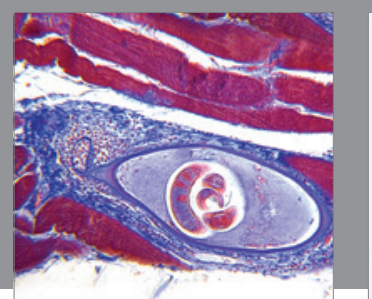

Gastroenterology Research and Practice

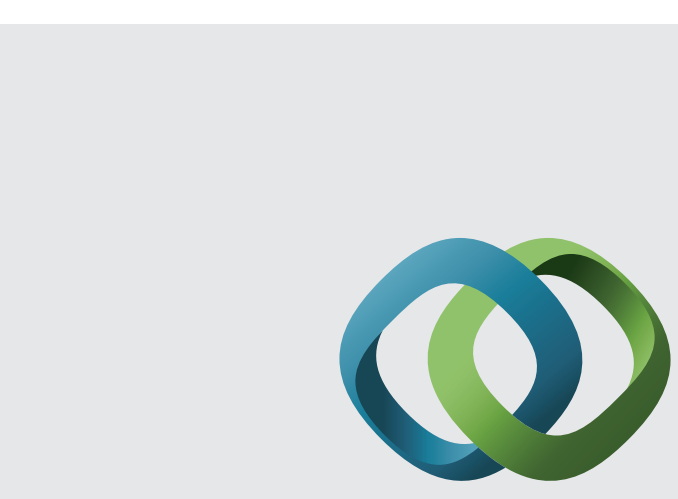

\section{Hindawi}

Submit your manuscripts at

http://www.hindawi.com
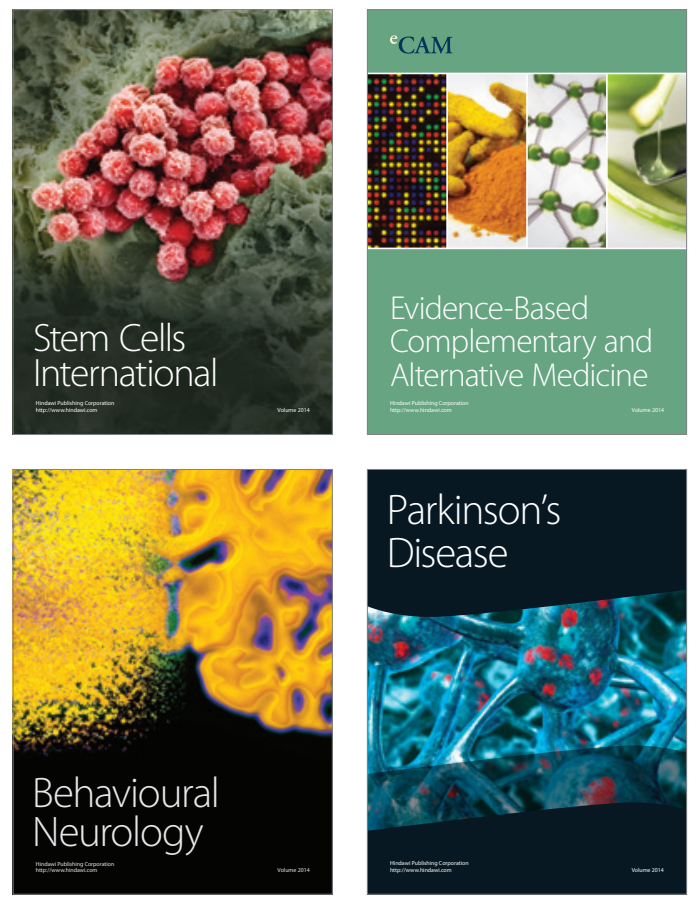
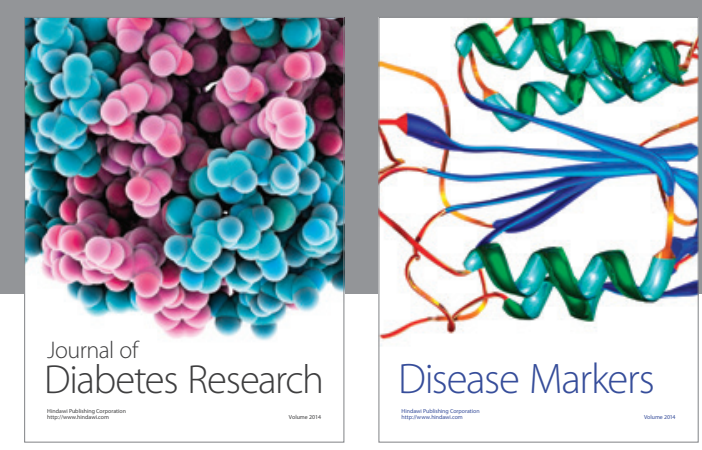

Disease Markers
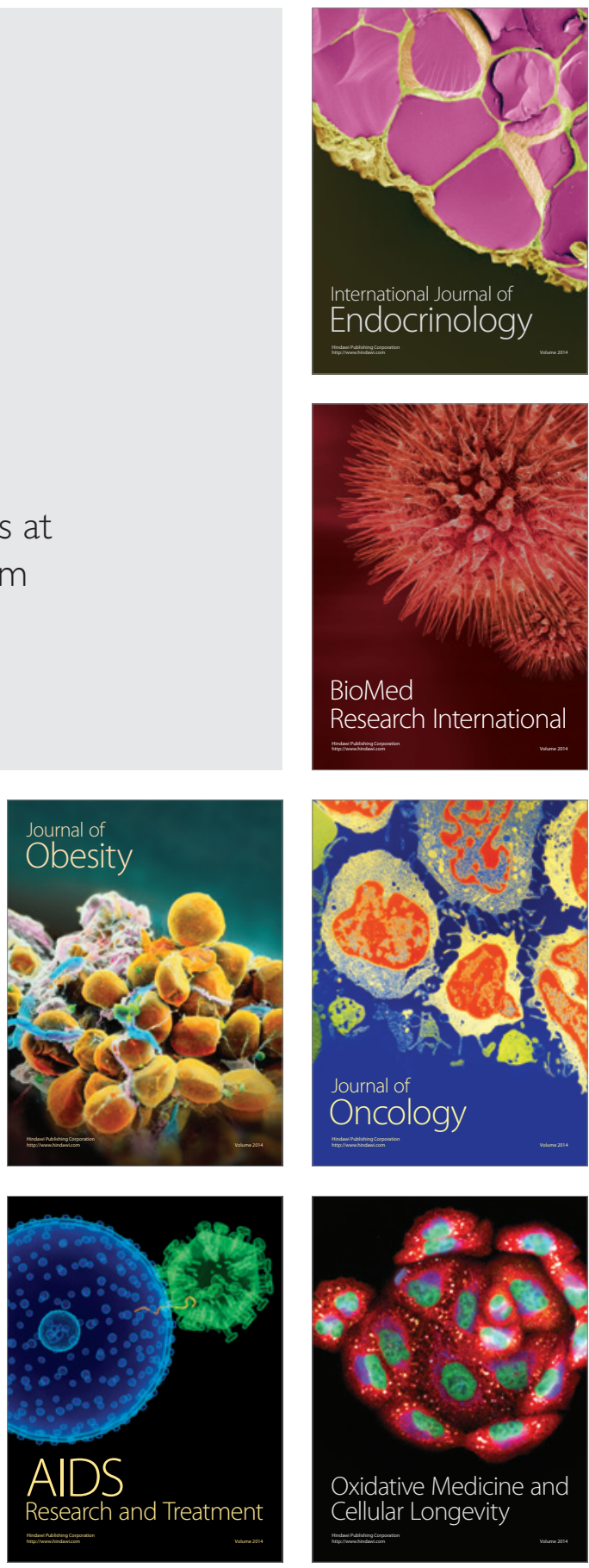